\title{
La Cerámica Protohistórica e Histórica en el yacimiento del Portalón de Cueva Mayor, Sierra de Atapuerca. Burgos
}

\author{
A. PÉREZ-ROMERO ${ }^{(1)}$; J. M. CARRETERO ${ }^{(1,4)} ;$ A. ALDAY(2); J. L. ARSUAGA ${ }^{(3,4)}$ \\ ${ }^{(1)}$ Laboratorio de Evolución Humana, Departamento de Ciencias Históricas y Geografía, Universidad de Burgos, Edificio I+D+i, \\ Plaza de Misael de Bañuelos s/n, 09001 Burgos, Spain. apromero@ubu.es; jmcarre@ubu.es; \\ (2)Departamento de Geografía e Historia, Universidad del País Vasco, C/ Tomás y Vicente s/n, 01006 Vitoria, Spain. (a.alday@ehu.es) \\ ${ }^{(3)}$ Departamento de Paleontología, Universidad Complutense de Madrid, Avenida Complutense s/n, 28040 Madrid, Spain. jlarsuaga@isciii.es \\ ${ }^{(4)}$ Centro UCM-ISCIII de Investigación sobre Evolución y Comportamiento Humanos, c/Sinesio Delgado, 4, 28029 Madrid, Spain.
}

En el Portalón de Cueva Mayor se encuentra una de las entradas actuales a la Cueva Mayor-Cueva del Silo, sistema kárstico situado en la Sierra de Atapuerca (Burgos, España). Se trata de un importante yacimiento arqueológico con una prolongada ocupación durante el Holoceno, apoyada con numerosas dataciones radiocarbónicas, la cual ha sido objeto de una serie de excavaciones desde los años setenta. Aquí presentamos y analizamos los restos cerámicos pertenecientes a los períodos protohistóricos (Edad de Hierro) e histórico (romanización, Edad Media y Edad Moderna Contemporánea). Para su contextualización se ha recurrido a la descripción de sus caracteres formales, funcionales y decorativos y a paralelismos con yacimientos regionales y nacionales de las mismas cronologías. La colección, que incluye aproximadamente 4000 fragmentos, no llama la atención ni por sus formas ni por su decoración, sin embargo, nos ayuda a explicar por qué esta cueva fue ocupada al final de la Prehistoria y, de forma esporádica, durante los tiempos históricos.

Palabras clave: Atapuerca, cerámica, Edad del Hierro, Romanización, Edad Media, Edad Moderna-Contemporánea.

Protohistoric and historic pottery at the site El Portalón of Cueva Mayor, Sierra de Atapuerca, Burgos

EL Portalón of Cueva Mayor is one of the present-day entrances to the Cueva Mayor-Cueva del Silo karst system located in the Sierra de Atapuerca (Burgos, Spain). It is an important archaeological site with extended Holocene occupation, supported by numerous radiocarbon dates, which has been subjected to a number of excavations since the nineteen seventies. Here we present and examine the pottery remains belonging to protohistoric (Iron Age) and historic (Romanization, Middle Age and Contemporary Modern Age) periods. Description of their shapes, functional and decorative features have been utilized as references for establish parallelisms with other sites sharing chronology both, at regional and peninsular levels. The collection, which includes approximately 4000 fragments, it is striking neither for its shapes nor for its decorations, however, it helps us to explain why this cave was occupied at the end of Prehistory and sporadically during historical times.

Keywords: Atapuerca, pottery, Iron Age, Romanization, Middle Age, Contemporary Modern Age.

\section{INTRODUCCIÓN Y ANTECEDENTES HISTÓRICOS}

Es común que en depósitos de la prehistoria reciente, los restos cerámicos constituyan el grueso del inventario. En esta situación es lógico que las ordenaciones cronoculturales que se proponen tomen las variaciones tipológicas —en formas y decoraciones- y técnicas de los elementos alfareros como uno de los argumentos principales.

La clasificación y adscripción cronológica de las producciones cerámicas elaboradas en un determinado periodo y en un ámbito geográfico concreto, y con suficiente respaldo de cronología relativa y/o absoluta, permiten transformar aquellos materiales extraídos de un contexto alterado en un registro comprensible. Este es el caso de una parte del material que vamos a presentar del yacimiento del Portalón: a aquellos lotes recogidos en contextos cerrados definidos estratigráficamente, sumamos otros recuperados en unidades revueltas cuyos caracteres, por específicos, permiten su adecuado encuadre cronocultural.
La Sierra de Atapuerca es una pequeña elevación situada a unos $15 \mathrm{Km}$. al Este de la ciudad de Burgos, en el límite oriental de la cuenca del Duero. Forma parte de las estribaciones del Sistema Ibérico, en el sector conocido como "Corredor de la Bureba", sirviendo de punto de contacto entre este sistema, la Cordillera Cantábrica y la Meseta. Desde el punto de vista estratégico su posición es privilegiada al coincidir ahí las vías de comunicación norte-sur que penetran hacia el interior de la Península Ibérica, con aquellas que se desarrollan esteoeste vinculadas con la Cuenca del Duero (Figura 1), lo que, como veremos, puede explicar una parte de las ocupaciones humanas que aquí se evalúan.

Las primeras referencias de Prehistoria reciente en Cueva Mayor de Atapuerca son de principios de siglo XX, a partir de las visitas realizadas por Carballo, Breuil ${ }^{2}$ y Obermauier ${ }^{3}$. En 1964, Jordá, entonces profesor de la Universidad de Salamanca, 


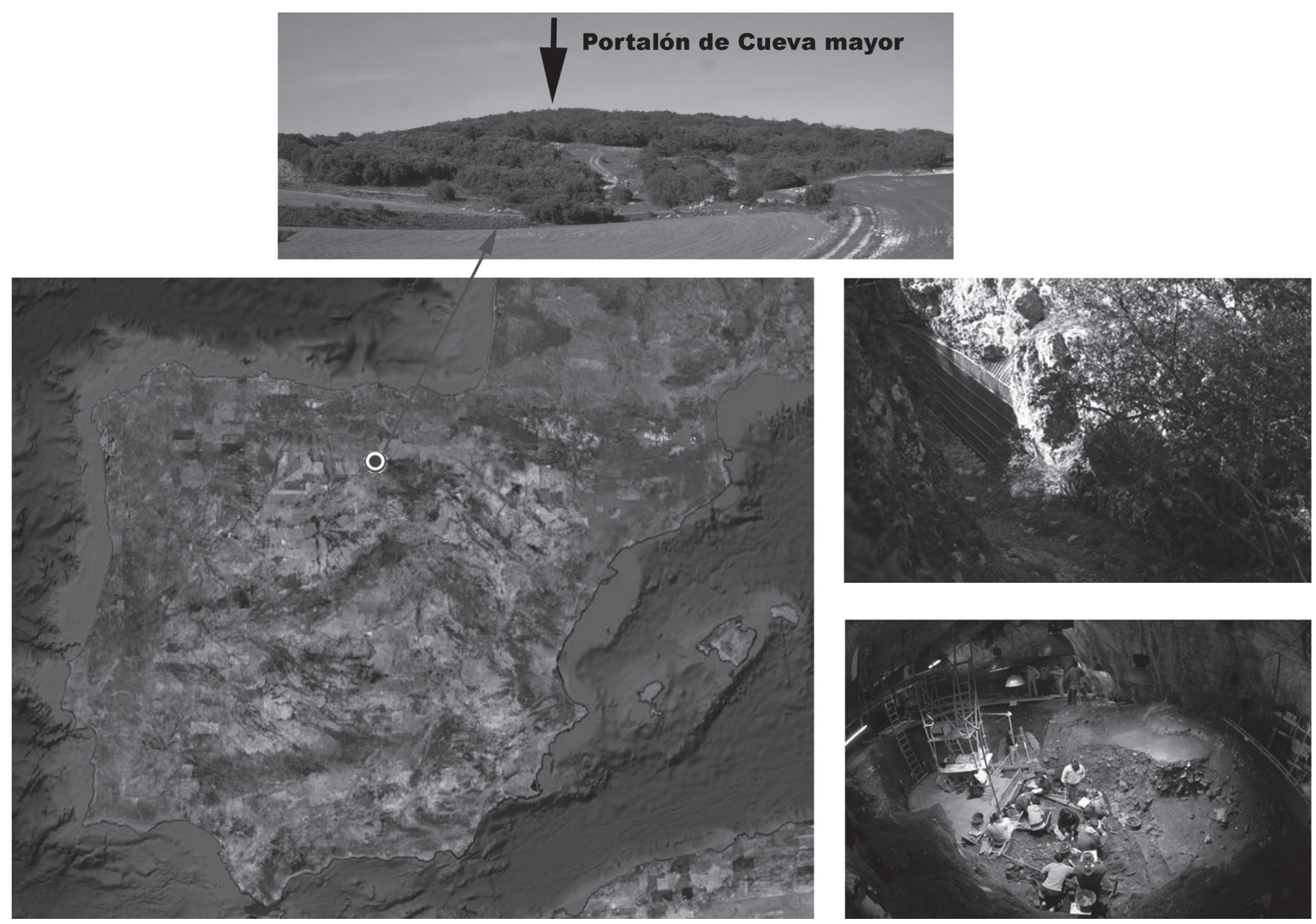

Figura 1. Situación geográfica de la Sierra de Atapuerca y localización del yacimiento del Portalón de Cueva Mayor.

realizó una primera excavación arqueológica en el depósito: sin embargo sus resultados nunca fueron publicados. En 1972, el investigador de la Universidad de Arizona, Clark, diseñando un plan de prospección de conjuntos del Paleolítico Superior de la Meseta Norte, realizó en el Portalón una intervención que puso de manifiesto una estratigrafía de 2,6 $\mathrm{m}$ de potencia. La serie integra 26 niveles, de los cuales los 7 superiores presentan evidencias confusas en las fases de ocupación 1 , especialmente en el periodo Romano -horizontes 1 y 3-. A partir del nivel 8 de detectan niveles in situ de la Edad del Bronce - horizontes 8 al 20-y el Eneolítico - horizontes 21 al $26^{4}$ -

La interesante secuencia cultural detectada por G. Clark motivó a J. M. Apellániz, profesor de la Universidad de Deusto, a proyectar una nueva intervención. Esta excavación, realizada entre 1973 y 1983, definió una serie de fases culturales donde se insertan materiales medievales y tardorromanos (Niveles I y II) y una importante ocupación de la Edad del Bronce (Nivel III). Esta ocupación fue a su vez subdividida, siguiendo criterios tipológicos y radiocronológicos, en: un conjunto del Bronce Final, un potente paquete del Bronce Medio y un horizonte del Bronce Antiguo.

\section{INTERVENCIONES ACTUALES}

Con el fin de conocer mejor el potencial arqueológico del Portalón, en el año 2000 iniciamos una nueva etapa de excavaciones realizadas por el Equipo de Investigación de Atapuerca (EIA), dirigido por Juan Luis Arsuaga e integrado dentro del proyecto de Investigación de Atapuerca (Figura 1). La obtención de una secuencia cronoestratigráfica que aunara y mejorara las informaciones anteriores, o la exploración de la cavidad en extensión y en toda su potencia sedimentaria, estaban entre los objetivos primordiales de nuestra intervención.

En nuestro trabajo, una vez delimitadas las áreas de actuación de las excavaciones previas, detectamos en el sector central del Portalón la presencia de una importante intervención que había pasado inadvertida, al carecer de cualquier referencia bibliográfica. Varias de las campañas de campo se dirigieron a parcelar los límites de dicha intervención: la evacuación de las tierras puso al descubierto antiguas labores mineras, aportando, además de una ingente cantidad de materiales arqueológicos, una amplia y consistente secuencia estratigráfica compuesta por dos grandes unidades sedimentológicas divididas a su vez en 11 niveles (0-10) (Figura 2). La datación radiométrica individualizada de cada nivel revela formaciones que abarcan desde el $34869 \pm 275 \mathrm{cal}$ a BP hasta el $886 \pm 91 \mathrm{cal}$ a BP (Tabla I). En concreto:

- Unidad superior: de cronología holocena (Niveles 0-9) se caracteriza por procesos de acumulación antrópica, consecuencia de la gran intensidad de ocupaciones que arrancando en el Mesolítico continúan por situaciones del Neolítico, el Calcolítico y la Edad del Bronce. Esta secuencia se completa con fases de ocupación protohistorica (N-2) e 


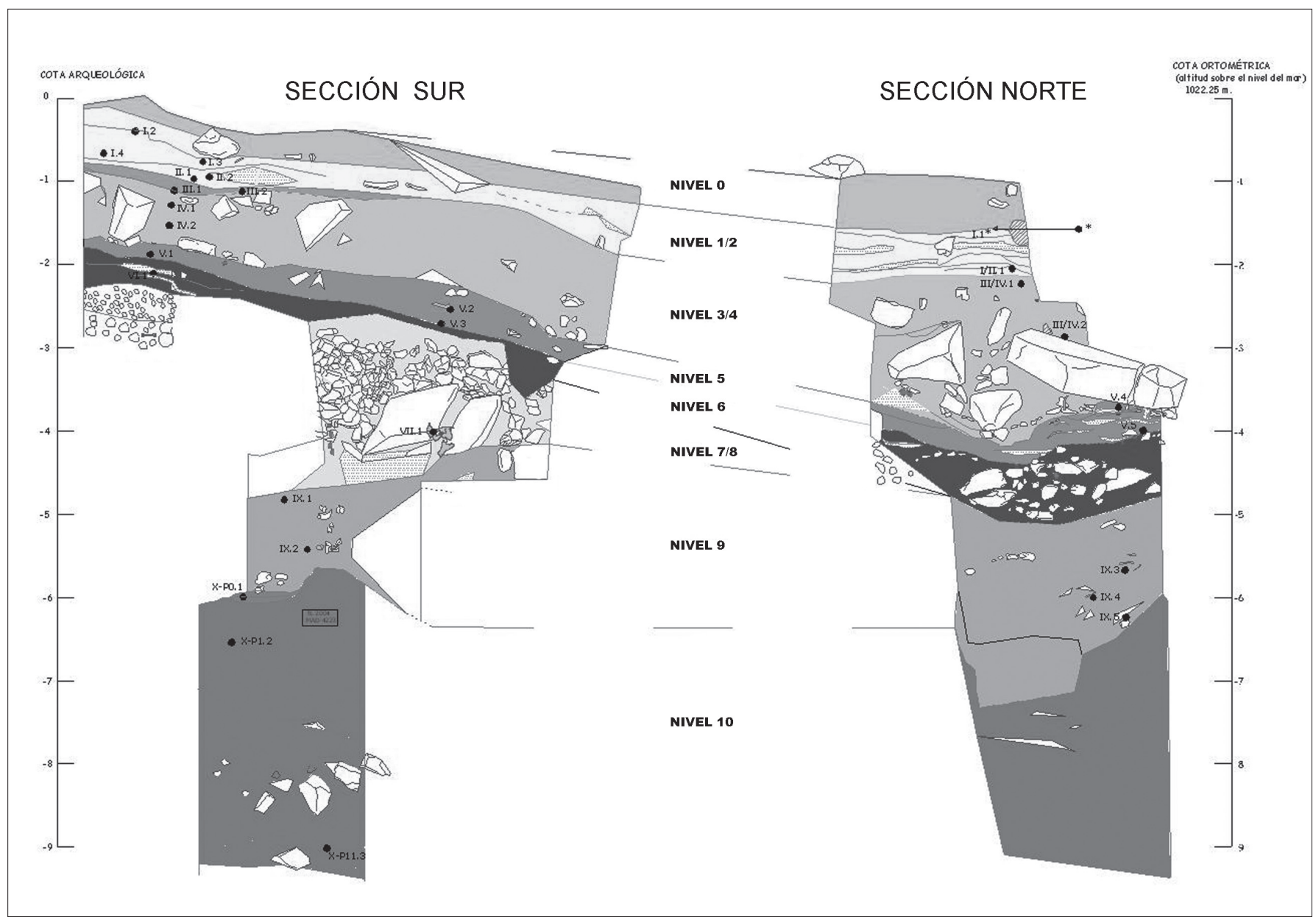

Figura 2. Secuencia estratigráfica del perfil Norte y Sur del Portalón de Cueva Mayor, con indicación de sus niveles.

Tabla I. Dataciones radiocarbónicas del Portalón de Cueva Mayor Realizadas por Apellániz. Y por el EIA. Fechas Calibradas usando la CURVA INTCA109. NO TENEMOS CONSTANCIA DEL TIPO DE MATERIAL RECOGIDO POR APELLÁNIZ PARA SUS DATACIONES CRONOLÓGICAS. LAS DATACIONES DEL EIA HAN SIDO COLOCADAS POR ORDEN CRONOLÓGICO.

\begin{tabular}{|c|c|c|c|c|}
\hline Laboratorio & Muestra & Material & $\begin{array}{c}\text { Fechas BP } \\
\text { (convencional) }\end{array}$ & $\begin{array}{l}\text { Fechas calibradas BP } \\
\qquad(2 \sigma)\end{array}$ \\
\hline \multicolumn{5}{|c|}{ Atapuerca-Portalón, España } \\
\hline \multicolumn{5}{|c|}{ Excavaciones de Apellaniz } \\
\hline C.S.I.C-531 & N III-1 & & 2850 & \\
\hline I-9879 & N III-2 & & $3170 \pm 50$ & $1550-1350$ \\
\hline C.S.I.C-611 & N III-4 & & $3640 \pm 50$ & $2190-1870$ \\
\hline \multicolumn{5}{|l|}{ Excavaciones del EIA } \\
\hline Beta-224081 & ATP,06-10-N1 & Hueso & $1000 \pm 40$ & $886 \pm 91$ \\
\hline Beta-212187 & ATP'05-2-N1a & Carbón & $1980 \pm 40$ & $1931 \pm 105$ \\
\hline Beta-153359 & ATP1.1PORTALÓN & Carbón & $2040 \pm 100$ & $2029 \pm 285$ \\
\hline Beta-201763 & ATP'04-N5-14C & Carbón & $2490 \pm 40$ & $2548 \pm 182$ \\
\hline Beta-222335 & ATP'06-1-N2 & Hueso & $2490 \pm 40$ & $2548 \pm 182$ \\
\hline Beta-197388 & $14 \mathrm{C}-2 \mathrm{~S}$ & Carbón & $2510 \pm 40$ & $2557 \pm 187$ \\
\hline Beta-209452 & ATP’06-P1-RP32 & Hueso & $16980 \pm 80$ & $20131 \pm 268$ \\
\hline Beta-212190 & ATP'05-5-P11-19 & Hueso & $30300 \pm 190$ & $34869 \pm 275$ \\
\hline
\end{tabular}

histórica (N-1 y N-0), siendo las producciones cerámicas de estos últimos momentos de ocupación el objeto de nuestro estudio ${ }^{7}$ (Figura 2).
- Unidad inferior: identificada como N10, se encuadra cronológicamente en el último tercio del Pleistoceno Superior (Figura 2). Como característica podemos señalar 
en ella una débil presencia de actividad humana entre 34 $869 \pm 275$ cal a BP) y $20131 \pm 268$ (Tabla I).

\section{CARACTERÍSTICAS DE LAS PRODUCCIONES CERÁMICAS PROTOHISTÓRICAS E HISTÓRICAS}

El presente trabajo revisa exhaustivamente la producción cerámica del yacimiento del Portalón de época protohistórica e histórica, atendiendo a sus diferentes factores: contextos culturales, evaluaciones tipológicas formales y decorativas, $\mathrm{y}$ cualidades técnicas del inventario (pastas y cocciones). También, para una mejor clasificación, nos hemos basado en la realizada en distintos yacimientos de referencia nacionales, próximos a nuestro entorno (Figura 3).

Situación geografica de los yacimientos mencionados en el texto

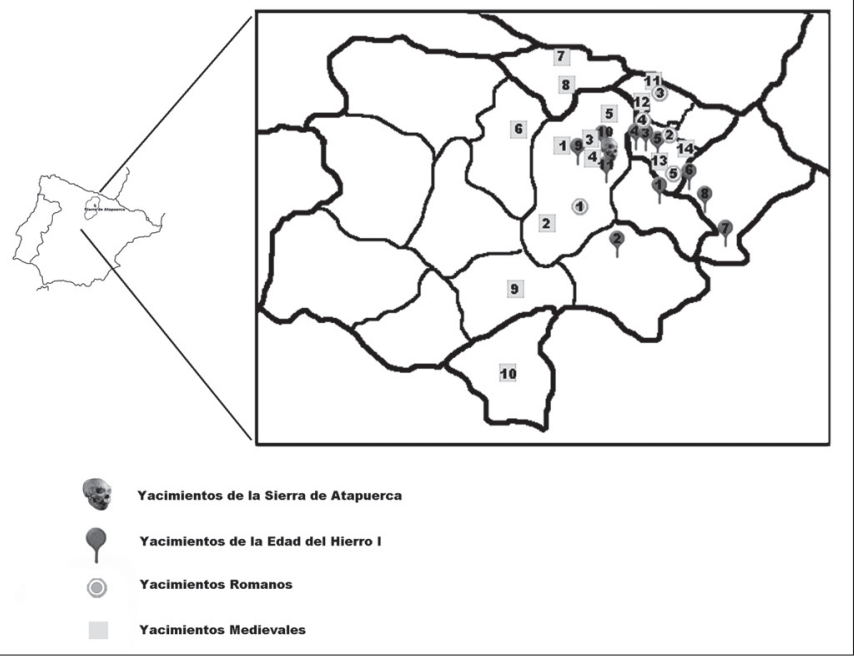

Figura 3. Yacimientos de referencia incluidos en el texto: Edad del Hierro: (1) El Redal (La Rioja); (2) Tiermes V y Carratiermes (Soria); (3) Berbeia , (4) Los Castros de Lastra y (5) La Hoya (Álava); en Navarra: (6) La Custodia, (7) El Castejón y (8) Castillar ; en Burgos (9) La Polera (10) Monasterio de Rodilla, (11) La Solana. Romanización: (1) Clúnia, Bugos; (2) Aloria, Álava, (3) Forua ,Bizkaia, (4) Iruña/Veleia, Álava, (5) Los Husos, Álava. Edad Media: (1) Castrojeriz; (2) Valdezate; (3) Cerro de San Miguel; (4) San Pedro de Cardeñay; (5) Monasterio de San Juan de la Hoz, Cillaperlata todos en Burgos; (6) Monte Cildá, Palencia; (7) Camargo; (8) Camesa, Santander; (9) Coca, Segovia; (10) La Indiana, Madrid; (11) Momoitio, Bizkaia, y en Vitoria-Gasteiz (12) Nuestra Señora de la Encina.

\section{Producciones Protohistoricas e Históricas}

$\square$ E. del Hierro $\square$ Romanización $\square$ E. Media $\square$ E. Mod.-Comt. $\square$ Indeterminados

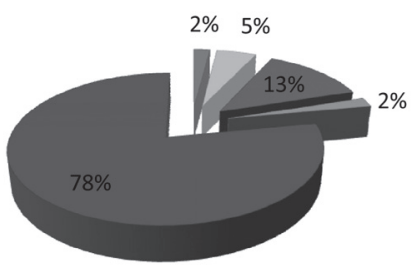

Figura 4. Representación porcentual de los fragmentos cerámicos distribuidos en sus entidades culturales de cronología protohistórica e histórica.
El inventario alfarero, sumando los correspondiente a cada una de las intervenciones, alcanzan los 30.000 fragmentos, de los cuales unos 3.900 son de las fases objeto de este estudio (Edad del Hierro I, Romanización, Edad Media y Edad Moderna-Contemporánea). (Figura 4)

\subsection{La Edad del Hierro I}

Para el material bien contextualizado hemos procedido a una clasificación tipológica y una ordenación morfológica. Esta operación nos ha servido de base para reordenar aquellos elementos en posición estratigráfica difusa procedentes de las diferentes excavaciones. El conjunto será clasificado, de acuerdo al tratamiento recibido en su elaboración, diferenciando en series de uso cotidiano (hogar, almacenamiento, cocina), y recipientes de uso específico: las primeras de fabricación mas tosca que las segundas, mejor decantadas y con decoraciones más elaboradas (Figura 5). Reconocemos el carácter intuitivo de esta organización, así como sus límites: sirven más a los propósitos de este trabajo que a las severas normas tipológicas.

Las intervenciones realizadas en la cavidad, pero especialmente las más recientes, han identificado un nivel arqueológico (NII) adscrito a la Edad del Hierro, concretamente

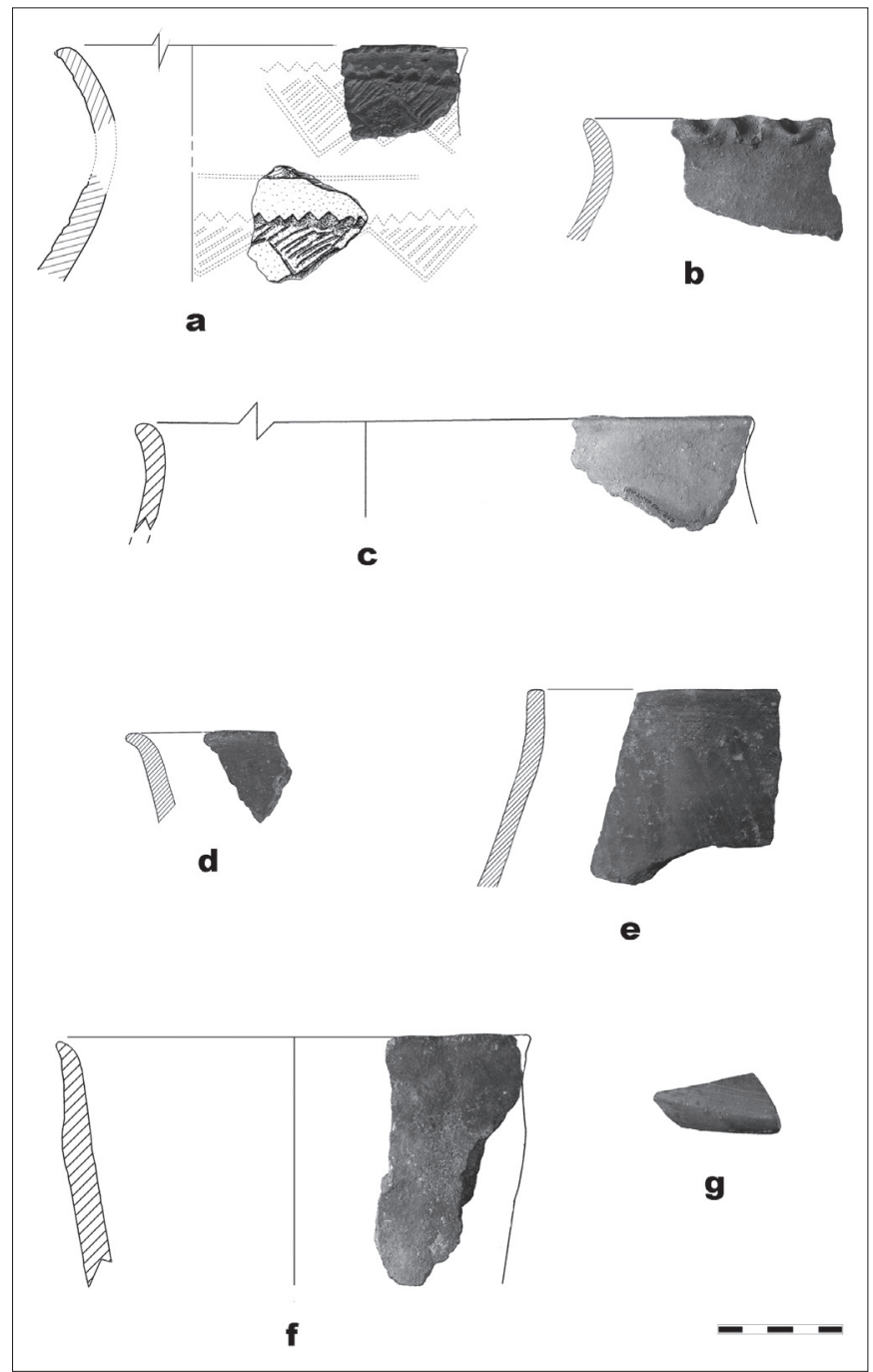

Figura 5. Conjunto cerámico adscrito a la Edad del Hierro. a): cerámica "de prestigio". b, c, d, e, f y g): cerámicas toscas o "de hogar". 
al Hierro I en su fase más tardía. El horizonte está compuesto por sedimentos de origen antrópico y orgánico donde alternan manchas cenicientas "fumiers" y limos arcillosos de tonos oscuros. Alcanza una potencia máxima de $30 \mathrm{~cm}$, y se ha contextualizado gracias a una amplia serie de fechas de C14 (Tabla I).

La colección cerámica está compuesta por 90 fragmentos (2\% del total de las estudiadas), que presentan uniformidad técnica y decorativa. Se trata de un conjunto fabricado a mano y cocido, mayoritariamente, en una atmósfera de tipo reductor, por lo que dominan las pastas las pastas de coloraciones negruzcas con oscilaciones tonales marrones y grisáceas, resultado de cocciones mal controladas. El acabado es, por lo general, tosco o simplemente alisado. Todos los fragmentos recuperados presentan desgrasantes entre los que dominan los minerales de la familia de la cuarcita y las calizas, elementos habituales en el entorno, de tamaño fino y medio.

Desde el punto de vista conceptual y de nomenclátor aplicamos la serie de términos de aplicación general, en cuyo significado y variabilidad seguimos los criterios de Armando Llanos y José. I. Vegas ${ }^{8}$ y de Amparo Castiella9, así como los estudios tipológicos propuestos por Francisco Romero ${ }^{10}$ y por Juan F. Blanco ${ }^{11}$.

\subsubsection{TIPOLOGÍA Y FUNCIONALIDAD}

De acuerdo con la división tipológica propuesta por Romero Carnicero ${ }^{10}$ estableceremos las siguientes series:

\subsubsection{De sintaxis elaborada o "de prestigio": (Vasos/Ollas)}

Han sido recuperadas en el Portalón dos fragmentos (2\%) de un mismo recipiente. Es la vajilla con decoración más rica, dispone en borde, cuello e inicio de la panza, frisos o cenefas cuyas amplitudes están en función de la anchura del hombro (Figura 5a).

\subsubsection{2. "De hogar" o comunes}

El conjunto de 88 fragmentos ha sido clasificado, en primer lugar, según la morfología general de sus perfiles: hemisféricos, globulares, ovoides, de perfil en "S" y carenados y en segundo lugar según la función que les suponemos: calentar, cocer o simplemente contener alimentos.

- Cocina/almacenaje. Caracterizados por ser objetos fabricados a partir pastas toscas a la que se han añadido abundantes desgrasantes. Las diferentes partes de las vasijas recuperadas presentan tal fragmentación que no hemos considerado oportuno su clasificación, que resultaría incierta. No obstante podemos distinguir, gracias a la forma de los bordes entre los pertenecientes a ollas/vasos, normalmente de cuerpo globular u ovoide, cuello corto y poco marcado. Suman 21 evidencias (23\%), pudiendo diferenciar entre ollas de borde abierto (13 fragmentos); (Figura 5b, c), ollas de borde exvasado (4 fragmentos) (Figura $5 \mathrm{~d}$ ) y de borde recto con labio plano (4 fragmentos (Figura 5e).

- Mesa/Consumo. Cuencos: aunque por norma se trata del tipo más característico, numeroso y difundido durante el Hierro ${ }^{12}$ no resulta así en el Portalón, ya que son 5 (6 \%) los fragmentos identificados como tales. Se caracterizan por sus paredes gruesas de acabados poco cuidados. Los bordes son rectos presentando una ligera curvatura al exterior en 2 casos con gran desarrollo vertical. (Figura 5f)

\subsubsection{TÉCNICAS DECORATIVAS}

Entre el lote cerámico de la Primera Edad Hierro del Portalón, son escasos los fragmentos decorados, caracterizados, además, por su sencillez, derivado, tal vez, por el mayoritario uso culinario y de cocina que se da a la vajilla.

El recipiente con sintaxis más elaborada conserva dos cenefas separadas por una franja sin decoración y bruñida, limitadas superiormente por una serie de pequeños triángulos excisos de los que cuelgan chevrons rellenos de entramados inciso (Figura 6a). Los otros casos refieren: a series de impresiones instrumentales (punzones y espátulas) (3 fragmentos); digitaciones o uñadas, casi siempre en la cercanía de los bordes o sobre ellos (2 fragmentos) (Figura $6 \mathrm{~b})$; incisiones lineales simples o agrupadas y siempre poco marcadas (un solo caso) (Figura 6g).

No es difícil, por la banalidad de los motivos, rastrear paralelos decorativos en la geografía adyacente, como por ejemplo son los casos de: El Redal ${ }^{13}$ (La Rioja); Tiermes V y Carratiermes $^{14}$ (Soria); Berbeia ${ }^{11}$ y Los Castros de Lastra y La Hoya $^{15}$ (Álava); La Custodia ${ }^{16}$, El Castejón ${ }^{16}$ y Castillar $^{16}$ (Navarra) y La Polera ${ }^{17}$, Monasterio de Rodilla ${ }^{18}$; La Solana ${ }^{19}$ (Burgos) (Figura 3).

\subsection{La Romanización}

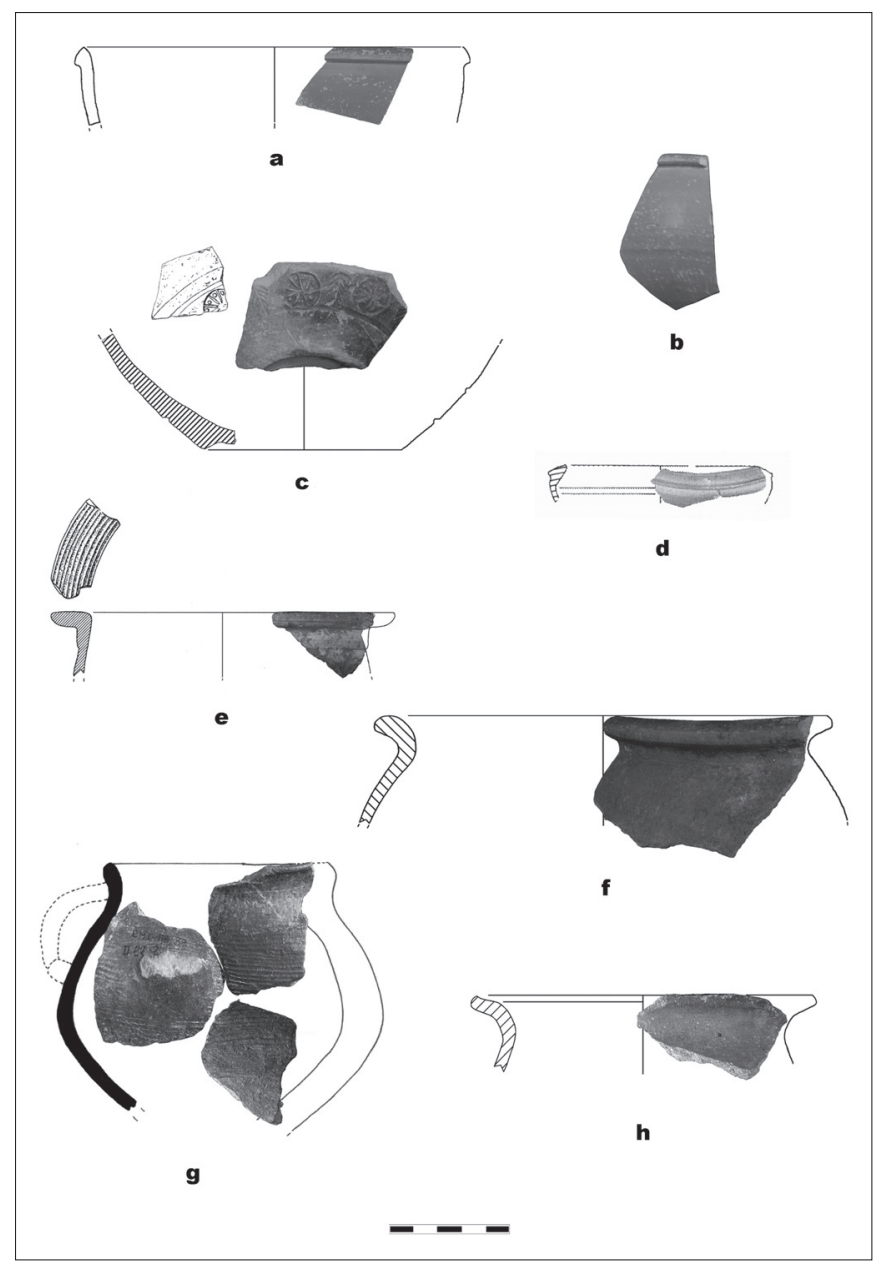

Figura 6. Conjunto cerámico adscrito a la Edad del Hierro. a) cerámica "de prestigio"; b, c, d, e, f y g) fragmentos de vajilla tosca o "de hogar". b) fragmento de borde decorado con digitalizaciones en el labio; c, d y e) fragmento de bordes de cerámicas toscas sin decorar; e) cuenco sin decorar; g) fragmento de galbo carenado. 
La cerámica romana se ha recogido en clara posición estratigráfica en los primeros niveles de la excavación de Clark; 2 de Apellániz y 1 de las excavaciones actuales (EIA), así como, en posición derivada, en el pozo minero antes aludido. Los horizontes intactos se corresponden con arcillas grises oscuras y pequeños clastos calizos, que han sido datados radiométricamente (Tabla I). Junto al inventario cerámico convive un repertorio interesante de objetos metálicos (clavos, arreos de caballería, joyas) y de fauna.

\subsubsection{TIPOLOGÍA Y FUNCIONALIDAD}

La producción la componen 193 fragmentos (un $6 \%$ del total de los materiales arqueológicos de adscripción protohistórica e histórica). Entre los que podemos diferenciar (Figura 6):

\subsubsection{Terra sigillata}

Siguiendo los corpus cerámicos que organizan estas producciones 22,23 hemos podido identificar 37 evidencias $(19 \%)$, diferenciando dos formas muy comunes, lo que indica la monotonía de la colección y el significado de la ocupación (Figura 6a, b y c):

- Ritterling 8. Corresponden a 3 fragmentos de bordes engrosados y de formas ligeramente almendradas y abiertos. Pertenecen a cuencos lisos esféricos o de paredes curvas $^{20,22}$. Están realizados con cocciones oxidantes, con pastas duras, de aspecto ligeramente poroso y relativamente homogéneo con abundantes inclusiones de grano fino y de naturaleza calcárea y micácea. La capa gresificada es densa, naranja brillante y relativamente mal conservado (Figura 6a y b).

- Dragendrorff 37. Representada por un fragmento galbo y otro de fondo, de la misma pieza, un cuenco que se conserva en algo más de su mitad. Las paredes son rectas y algo abiertas hacia el exterior y fondo plano. Está considerada como una variante decorada de producciones de terra sigillata hispánica e hispánica tardía ${ }^{23}$ (Figura 6c).

Los 32 fragmentos restantes corresponden a galbos y un pequeño fondo que no permite la reconstrucción formal de las vajillas.

\subsubsection{Cerámicas de "paredes finas"}

A nivel general esta categoría reúne boles, tacitas lisas o decoradas, cuencos, copas, botellas... caracterizadas por sus paredes delgadas, recubiertas o no de engobe.

En el caso del Portalón se han identificado tres fragmentos ( $2 \%$ ) correspondientes a dos ollitas que copian los modelos Lamboglia 51/52 de la cerámica Campaniense ${ }^{24}$ (Figura 6d). Presentan pastas duras y porosas de color blanquecino, tendente a ocre-blanquecino, con algunas vacuolas y pequeños y escasos desgrasantes de color ocre oscuro y de mica.

\subsubsection{Cerámica común}

Esta producción es en el Portalón, con diferencia, el elemento artesanal más abundante, ya que se han recuperado 153 fragmentos reconocidos alcanzando al $79 \%$ de la cerámica. Las tonalidades de las superficies varían entre el gris claro y el gris oscuro, pudiendo observarse también tonos ocres y naranjas. Las pastas están poco depuradas, con aspecto granuloso e inserción de abundantes desgrasante minerales de calibre medio y grueso, generalmente calizas, cuarcitas y micas e incluso algunos vegetales. Mayoritariamente parecen haber sido modeladas con torno rápido sin tratar las superficies, salvo un ligero alisado exterior, razón por la cual presentan un aspecto grosero y áspero al tacto (Figura 6e, f, g y h). Las pastas de este conjunto no se apartan en sus caracteres con lo descrito en otras cavidades ${ }^{25,27}$ (Figura 3).

Entre las formas reconocidas determinamos tres usos:

- Vajilla de Cocina.

Ollas.- Tienen como finalidad cocer los alimentos. Como rasgo general presentan cuerpo ovoide y fondo plano y están realizadas mayoritariamente a torno, con la superficie exterior alisada. Presentan color marrón rojizo o gris con abundante desgrasante de micáceos. Las hay de labio horizontal plano decorado con líneas incisas y engrosado en su parte externa, dando lugar a una sección casi triangular del borde (2 fragmentos) (Figura 6e) y de borde vuelto hacia el exterior con labio de contorno redondeado, y curvo (10 fragmentos) (Figura 6f). El cuello suele ser estrangulado y corto, el cuerpo ovoideo y los fondos, por lo general, planos.

- Servicio y contención de líquidos: Jarras/ cantaros.

Presente en 2 recipientes de boca estrecha, cuello cónico cerrado y borde ligeramente saliente con labio redondeado. Bajo el borde presentan el arranque de un asa de cinta que descansa en la panza (Figura $6 \mathrm{~g}$ ). Son producciones torneadas que, normalmente no son frecuentes en los yacimientos del norte peninsular, estando adscritas a talleres del entorno del valle Medio del Ebro ${ }^{28}$.

- Almacenaje.

La forma predominante muestra un cuerpo esférico, borde engrosado al exterior y vuelto, en algunas con una concavidad en el interior del mismo para el ajuste de la tapadera, la base posiblemente fuera plana (Figura 6h).

\subsubsection{TÉCNICAS DECORATIVAS}

\subsubsection{Terra sigillata}

Siguiendo a Mayet $^{29}$ el estilo decorativo reconocido en las terras sigillatas del Portalón se encuadran en la fase hispánica tardía. Los dos fragmentos considerados aportan series circulares con estampaciones internas separadas por espigas verticales, todo enmarcado con sendas líneas incisas paralelas. La sintaxis debe situarse en torno al siglo II-III d.C., tomando especial interés entre los siglos IV a principios del $\mathrm{VI}^{23}$ (Figura 6c).

\subsubsection{Cerámica Común}

Por regla general las producciones comunes romanas del Portalón son formas lisas de paredes alisadas, algunos fragmentos presentan decoraciones a base de incisiones. Suelen disponerse sobre los hombros o en la panza, y, en dos casos, en el borde.

- Motivos Lineales: realizadas con un instrumento afilado aprovechando la rotación del torno. Se trata de un tipo de decoración muy generalizado en la cerámica común de los siglos III a V en el Occidente del Mediterráneo (Figura $6 e)$.

- Acanaladuras o estrías: realizadas con un instrumento de punta roma, aprovechando también la rotación del torno. 
Normalmente aparecen en cuello, panza e incluso en los bordes de labios (Figura 6e).

- Incisiones a peine: se realiza sobre la superficie del recipiente cuando ya ha adquirido la consistencia del cuero con peine de material vegetal, metal o hueso (Figura $7 \mathrm{~g}$ ).

\subsection{La Edad Media}

Durante el siglo $X$ en el territorio se lleva a cabo una reestructuración centrada en la fundación de núcleos urbanos, con el consabido agrupamiento de la población en torno a estos, o de cenobios religiosos. Las cavidades fueron, entonces, ocupadas de manera muy ocasional o anecdótica, tal vez de forma prolongada, pero discontinua, por parte de una población flotante dedicada a actividades agrícolas, ganaderas o asociadas a la explotación de las materias primas del entorno: madera, piedras, caza. La presencia de estas gentes ha dejado en la cavidad su huella con la presencia de su vajilla, sin tener constancia de otro tipo de materiales arqueológicos.

En nuestro caso, la ocupaciones de época medieval están avaladas por las cronologías y los inventarios cerámico de esos niveles ( 1 al 3 de Clark; I y II de Apellániz y 0 de las intervenciones actuales), así como por las características técnicas, decorativas y tipológicas propias de estas fases (compartidas por otros fragmentos del conjunto revuelto de la Cata $\mathrm{W}$-pozo).

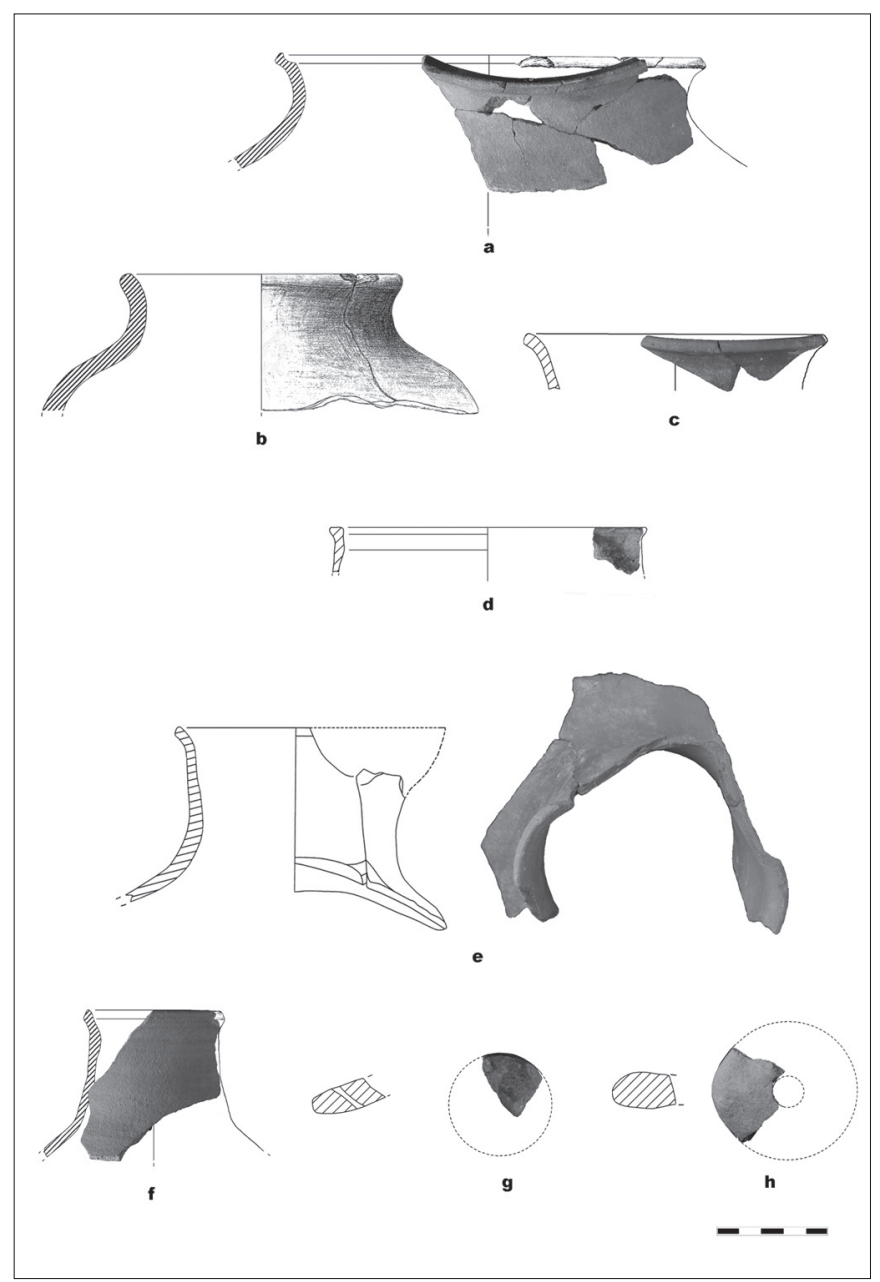

Figura 7. Conjunto de cerámicas medievales. a, b c y d): recipientes destinados a la uso culinario; e y f): recipientes destinados al servicio y contención de líquidos; g y h): elementos auxiliares y multifuncionales.

\subsubsection{TIPOLOGIA Y FUNCIONALIDAD}

A grandes rasgos esta cerámica se caracteriza por pastas de aspecto arenoso, con una fuerte inclusión de cristales de calcita y/o cuarzo de todos los tamaños. Elaboradas a torno, ofertan la mayor diversidad morfológica y tipológica del repertorio que estudiamos. La cocción se efectuó, mayoritariamente, a baja temperatura en una atmósfera predominantemente reductora $(65 \%)$. No obstante la variedad de los tonos de las paredes, que oscilan del gris claro al negro, pasando por ocres y marrones-grisáceos y en bastantes casos con resultados rojizos y amarillentos, nos habla del control que se tenía en la utilización de los hornos. Somos conscientes, además, que dada la naturaleza para la que fueron realizadas estas piezas (cocina y almacenaje) y por consiguiente la continúa exposición al fuego de muchas de ellas, se ha producido una notable variación del color de las pastas originales.

En lógica, también para este conjunto, que suman casi 600 efectivos, hemos seguido su sistematización partiendo de criterios funcionales ${ }^{30}$. Así reconocemos 3 series que pueden a su vez presentar un número indeterminado de formas (Figura 8):

\subsubsection{Recipientes para uso culinario}

- Ollas. Se trata del grupo mejor representado entre la vajilla de cocina (74 \%). Presentan formas globulares, cuellos cortos y bordes abiertos/exvasados escasamente desarrollados, con un mayor grosor que el resto de las paredes de la pieza. Es común una marcada inflexión, a modo de estrangulamiento, entre el borde y el hombro, y siendo los fondos planos. Dentro de las ollas diferenciamos:

- Borde abierto con cuello muy corto y curvado (50\%). El labio suele ser biselado al exterior y presenta una muesca interior para encajar una tapa (Figura 7a).

- Borde exvasado con labio redondeado y cuello corto $(30 \%)$ (Figura $7 \mathrm{~b})$.

- Bordes abierto con labio biselado al exterior (12\%) (Figura 7c).

- Borde apestañado, más o menos desarrollado, con amplio reborde exterior y labio ligeramente redondeado $(8 \%)$ (Figura $7 d)$.

Las ollas pueden ir acompañadas de elementos sustentantes, sobre todo asas de cinta con perforaciones mediante puntos incisos.

\subsubsection{Recipientes para servicio y contención de líquidos}

- Jarras: (10\%) representadas por recipientes con cuellos cónicos, borde ligeramente saliente, labio redondeado y boca como vertedor. El exterior de las paredes ha sufrido, por norma general, un tratamiento superficial de alisado (Figura 7e).

- Cántaros: $10 \%$ del total, realizados en pastas grises con abundantes desgrasantes de caliza y cuarcita de pequeño tamaño. El cuello está bien desarrollado con una pequeña moldura y el borde es recto biselado al exterior. Estas piezas suelen tener asas (1 ó 2) y fondo plano (Figura 7f).

\subsubsection{Elementos auxiliares y multifuncionales}

Presentan una frecuencia muy escasa $(2 \%)$, pudiendo reconocer entre ellos lebrillos, tapas (Figura $7 \mathrm{~g}$ ) y fusayolas (Figura 7h). 


\subsubsection{TÉCNICAS DECORATIVAS}

En la cerámica de esta época dominan ampliamente los recipientes lisos, si bien los entre los escasos ejemplares decorados $(20 \%)$, se oferta una cierta variedad de soluciones. Las técnicas empleadas son (Figura 8):

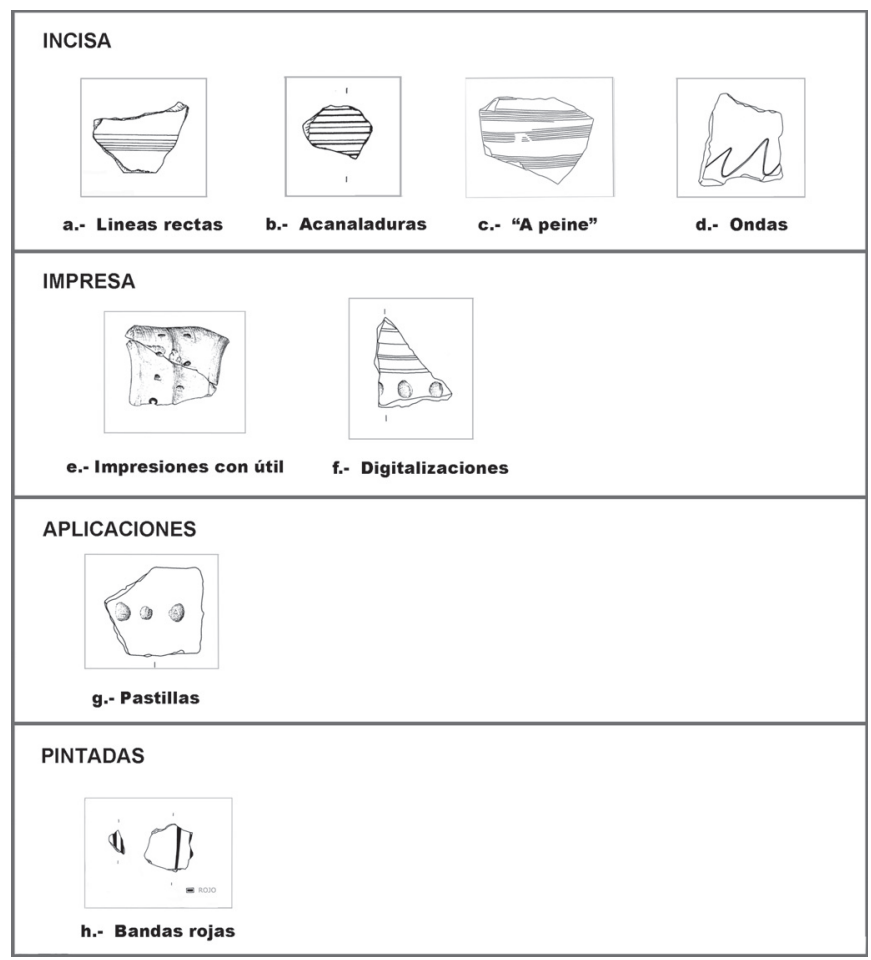

Figura 8. Tipos de decoración en las cerámicas medievales. a, b, c y d): decoración incisa; e y f): decoración impresa; g ): decoración aplicada; h): decoración pintada.

\subsubsection{Incisión}

Incisión, como el recurso más empleado (70 \%), a menudo usando instrumentos de punta roma que generan acanaladuras de ancho variable. Entre los motivos documentamos:

- Lineales rectos (Figura 8a), de desarrollo horizontal y continuo, en una o varias líneas paralelas.

- Acanalada (Figura 8b), la segunda en importancia, resaltando aquellas con incisiones paralelas regularizadas en la superficie que producen un efecto de claro-oscuro que embellecen la pieza.

- "A peine" (Figura 8c), en dos fragmentos de una misma pieza agrupando las series en bandas

- Ondas (Figura 8d), sorprende que siendo esta seña de identidad en los yacimientos Castellano-Leoneses apenas aparece entre el material del Portalón de Cueva Mayor, tan solo dos galbos

\subsubsection{Impresión}

Es la segunda técnica en importancia $(15 \%)$ y entre esta técnica decorativa hemos podido distinguir:

- Las que emplean un útil (Figura 8e): cuando se ejecutan sobre las asas tiene, además una intención funcional, facilitando el mejor agarre de las piezas.

- Digitaciones (Figura 8f), son muy escasas, disponiéndose principalmente sobre las asa y, en menor proporción, en la panza.

\subsubsection{Pastillas}

Como elemento plástico (Figura $8 \mathrm{~g}$ ). Único ejemplar que corresponde a un fragmento de borde de vaso de boca recta, disponiendo los apliques en paralelo al borde.

\subsubsection{Pintadas}

Cuatro fragmentos sobre los que se usan tintes rojos vinosos distribuidos en bandas verticales sobre la panza (Figura 8h).

\subsubsection{Combinación de técnicas (Impresión-Incisión)}

Presente en un fragmentos en el que se aprecian impresiones digitalizadas con líneas incisas horizontales y paralelas (Figura 8f)

La colección alfarera de El Portalón comparte los caracteres morfológicos con las series que nos han servido de cotejo: por un lado, producciones recuperadas de la misma provincia (Castrojeriz ${ }^{31}$, Valdezate ${ }^{32}$, Cerro de San Miguel ${ }^{33}$, San Pedro de Cardeña ${ }^{34}$, Monasterio de San Juan de la Hoz, Cillaperlata ${ }^{35}$, y series recopiladas en prospecciones ${ }^{33}$, además de colecciones de provincias próximas a Burgos: Monte Cildá $^{36}$ (Palencia); Camargo ${ }^{37}$ y Camesa $^{38}$ (Santander); Coca ${ }^{39}$ (Segovia); La Indiana ${ }^{39}$ (Madrid); necrópolis de Momoitio ${ }^{40}$ (Bizkaia) y, el Santuario de Nuestra Señora de la Encina ${ }^{41}$, la Basílica de San Prudencio ${ }^{42}$ y los Castros de Lastra ${ }^{43}$ (Álava) (Figura 3).

\subsection{Cerámica Moderna-Contemporánea}

Aunque en general el repertorio cerámico de adscripción histórica reciente suele pasarse por alto en los depósitos arqueológicos en cueva, nos ha parecido oportuno tratarlas como una entidad más, con su propia personalidad. Son restos escasos y poco concluyentes a la hora de precisar su cronología, por ser cerámica muy común, sin apenas cambios, entre principios del siglo XVI a la primera mitad del siglo XIX, cuando la Revolución Industrial impone la paulatina desaparición de los alfares tradicionales en pos de una producción industrial ${ }^{44}$.

\subsubsection{TIPOLOGIA Y FUNCIONALIDAD}

Dado el montante restrictivo de nuestra colección, 85 casos, nos parece suficiente la división entre piezas esmaltadas y no esmaltadas (Figura 9), incluyendo en las últimas las que presentan algún tipo de vidriado.

\subsubsection{Esmaltado}

Cerámicas esmaltadas con vidriado estannífero, que cubre toda la superficie y que dan a la pieza un tono blanco uniforme y muy brillante está compuesta por 10 fragmentos. Sobre el vidriado de las piezas cerámicas se trazaban dibujos con pinturas vitrificantes mediante la aplicación de compuestos de manganeso para conseguir colores como el negro-morado o el verde por la adicción de cobre (Figura 9a y b).

El elenco formal se restringe casi exclusivamente a vajilla destinada a la mesa, siendo el cuenco o escudilla y la jarra las formas más representadas junto al plato.

\subsubsection{No esmaltado}

- Se han recuperado 12 fragmentos que corresponden, por lo general, a vajilla de cocina realizadas en pastas sedimentarias, muy bien decantadas, con cocciones 


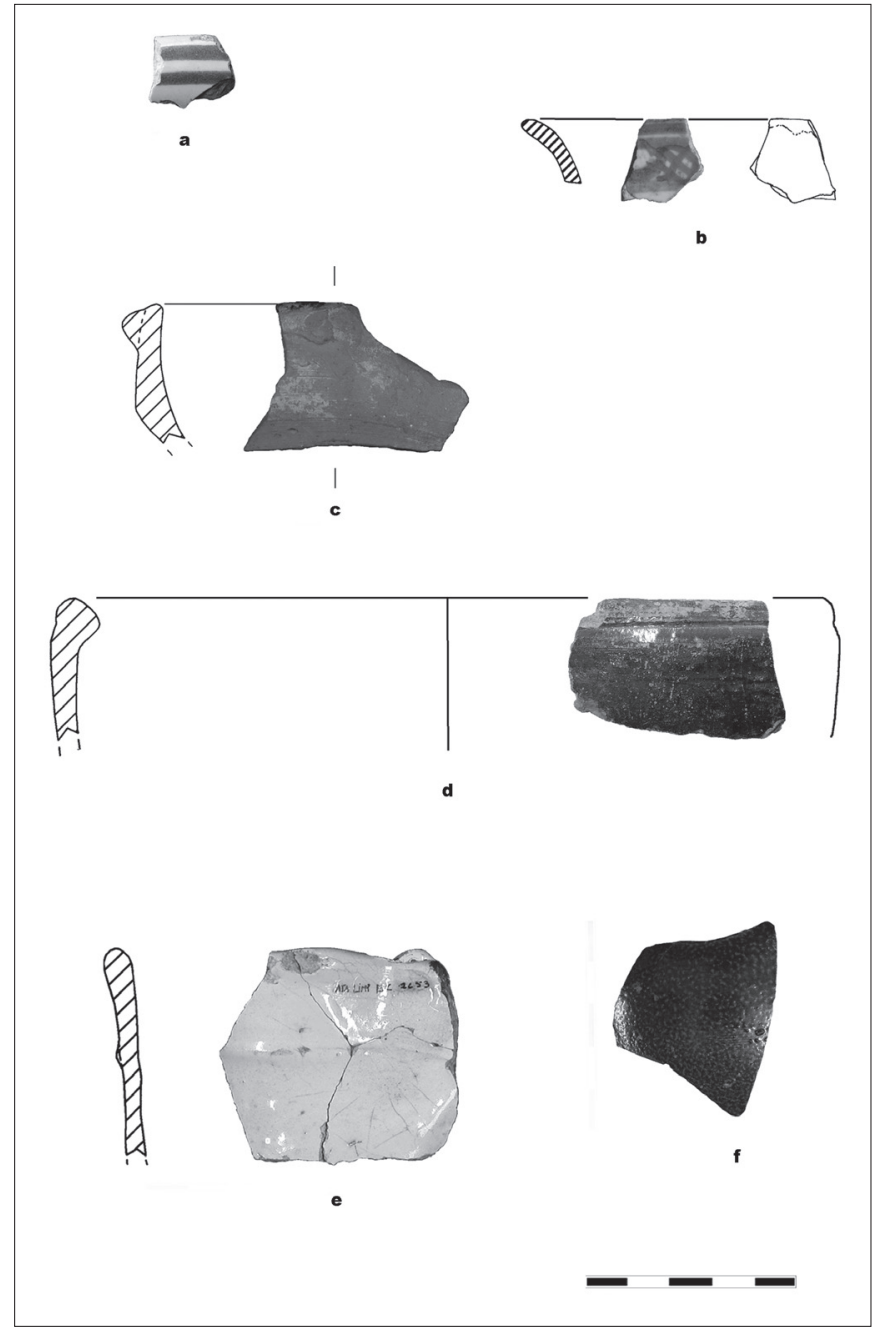

Figura 9. Conjunto cerámico de adscripción Moderna Contemporánea. a y b): cerámica esmaltada; e): cerámica con vidriado estannífero; c, d y f): cerámicas no esmaltadas.

oxidantes (pastas naranjas) y tratamiento exterior alisado. No presentan decoración. Conviene menciona aparte las denominadas "bizcochada" (Figura 9c), que puede abarcar piezas rusticas de almacenaje, útiles de cocina o bien elementos de mesa.

- Vidriado. Recipientes alisados tanto al interior como al exterior a los que se añaden vidrios monocromos para la cubrición total o parcial de las paredes. Este vidriado transparente, combina plomo, arena y sal común fundida y bien molida, que mezclados con agua se aplica, por inmersión o vertido, antes de la cocción: impermeabiliza a las vasijas a la vez que las dota de brillo y color. En nuestra colección distinguimos:

- Melada (Figura 9d): grupo que engloba 59 fragmentos, que presentan como acabado final, total o parcial, este tipo de técnica.

- Vidriado estannífero (Figura 9e): Se trata de una pieza no decorada pero en la que puede apreciarse que se ha realizado un vidriado blanco a base de estaño fundido con plomo.

- "A la sal" (Figura 9f) (3 galbos de una misma pieza). Se logra bañando el vaso en sal o cloruro sódico humedecido que por la acción del calor procedente del horno se descompone en gases de sodio y ácido clorhídrico. El sodio actúa como fundente y reacciona con el sílice iluminando el cuerpo de la arcilla. Su procedencia parece Renana, por las características técnicas que presenta, difundiéndose en los siglos XVI-XVII por toda Europa, y llegando a Gran Bretaña y desde allí posiblemente a España (J. L. Ibarra: comentario personal).

\subsubsection{TÉCNICAS DECORATIVAS}

La ornamentación de este conjunto cerámico, tanto en las producciones esmaltadas como sin esmaltar, es de poca variedad en gamas cromáticas y motivos ya que tan solo hemos podido detectar:

\subsubsection{Linea azul "Yayal blue on white".}

Presentan diseños lineales sobre fondo blanco en dos casos, situados en los bordes o en las alas de los platos ${ }^{45,46}$ (Figura 9a).

\subsubsection{Etapa manierista}

En los siglos XVI y XVII se desarrolla esta técnica caracterizada por la fabricación de platos en pastas blancas y sobretodo por la aparición como motivo decorativo más destacado, dentro de las series talaveranas, de la denominada "serie Tricolor" u "orla Castellana" (Figura 9b), consistente en la combinación de los colores azul-morado, naranja y negro.

\section{CONCLUSIONES}

La ocupación de cavidades en los primeros compases de la Historia lejos de ser un fenómeno marginal, alcanza una amplia dispersión geográfica como lo demuestran los estudios realizados en áreas próximas al yacimiento del Portalón: Cordillera Cantábrica y Meseta norte ${ }^{47,}$, , País Vasco ${ }^{26,27,}$ 45, La Rioja ${ }^{50}$ o los Pirineos $^{51}$. Estamos ante a un proceso complejo (social, estructural, económico), no lineal, que muy probablemente no puede ser explicado atendiendo a una única causa. En esta situación se trata es un problema histórico en permanente revisión como lo demuestran las recientes publicaciones bibliográficas llevadas a cabo por autores como: Barrios y Martín ${ }^{52}$, Riaño 199527, 53 .

La ocupación de cuevas y abrigos en plena Edad del Hierro es un fenómeno relativamente frecuente en nuestro entorno geográfico: por ejemplo Solacueva de Jócano, Covairada y Los Husos I en Álava; Cofresnedo en Cantabria, Tragaluz, Cueva Lóbrega y San Bartolomé en La Rioja, o La Peña de Marañón en Navarra (para esta vale como referencia: Cava, A. y Beguiristain, M.A., 1991-1992, El yacimiento prehistórico del abrigo de la Peña (Marañón, Navarra), Trabajos de arqueología Navarra, No 10, 69-166). Parecen, y El Portalón no se escapa de esta regla, asentamientos temporales, transitorios, que cumplen acciones complementarias respecto a los poblados estables situados en las inmediaciones (en nuestro caso Tritium; Monasterio de Rodilla, Cerro de San Miguel). Seguramente sirven para el desarrollo de actividades económicas aparentemente menores, pero claves para lograr una explotación integral del medio: en un entorno como el de la Sierra de Atapuerca, seguramente pastoreo, caza y/o aprovisionamiento de leña). Quienes 
se instalan acuden con unos ajuares muy pobres: entre la cerámica vajillas para el día a día, la cocina y el almacenaje. En El Portalón, la presencia de estructuras de tipo "fumiers" nos indica la importancia que aquí tuvo la gestión ganadera, que da sentido a las ocupaciones anteriores de las edades con metal.

La inestabilidad política y social del Bajo Imperio Romano, y la desestructuración económica que esta situación provoca, es causa para que, de nuevo, las gentes miren a las cavidades como lugares de refugio en momentos de peligro, así como alternativa económica, idea que en otros contextos han esgrimido Gurt y Palet ${ }^{51}$ y López Rodríguez ${ }^{54}$. En este sentido, y en parte como alternativa explicativa, es posible que la presencia de materiales en el enclave, podría venir dada por un incremento de la actividad agrícola y ganadera en la época, que revalorizaría los pastos de la Sierra de Atapuerca y su cuevas como refugio, lugar de descanso y de protección (no verdaderamente como establo). En estas coordenadas podemos entender la nueva ocupación en El Portalón, por un grupo que, a juzgar por el número de restos, ni fue numeroso ni desarrolló actividades muy intensas, aunque comprendemos que para evaluar mejor la situación, quedan por realizar estudios más exhaustivos.

Una circunstancia adicional que no debe pasarse por alto, es la situación estratégica del lugar. Efectivamente, por las inmediaciones de la cueva discurre una vía secundaria, ramal de la Asturica Burdigalam que uniría, a través de la Sierra, las ciudades de Tritium Autrigonium hacia la comarca de Lara y de aquí a Clunia. El Portalón bien pudo ser un adecuado lugar de descanso o de refugio ${ }^{46}$.

Y la vida, de manera discontinua, prosigue en el Medievo: tal vez como escondrijo de bienes de equipo o de personas; o como lugar donde almacenar y manipular la comida mientras se trabaja en sus inmediaciones; o como residencia temporal de pastores, leñadores, cazadores, y de todo aquel que aproveche los recursos naturales del entorno. Nos explica el hallazgo de los restos arqueológicos de tipología medieval recuperados, como parte de pequeñas historias dentro de la Historia general. Una de estas "pequeñas historias" tal vez tenga que ver con el paso del Camino de Santiago en sus proximidades: tanto por la vertiente norte de la Sierra (tramo de San Juan de Ortega a Atapuerca) como en la sur (tramo de San Juan Ortega a Ibeas de Juarros).

Queremos concluir señalando que los inventarios alfareros de los últimos momentos de ocupación El Portalón, responde a ocupaciones discontinuas, especializadas, realizadas por grupos no muy numerosos que se dedican, en las circunstancias sociopolíticas que imperan en cada momento, a actividades menores o complementarias. Si acertamos en las razones de estas ocupaciones, creemos entender que lo que en realidad les interesaba no era la cavidad en sí misma -amplia si, pero también fría y húmeda con pocas horas de insolación diaria- tanto como los paisajes y sus productos por explotar. Evidentemente, acudir al Portalón es una más de las soluciones del entramado habitacional, tan variado en aquellos momentos. Son, por tanto, ajuares para la vida cotidiana, necesarios para el acomodo de aquellas gentes, pero de factura corriente, que se abandonan tras su uso o rotura. Objetos que, hay que reconocerlo, poco valor tienen en las reconstrucciones arqueológicas, pero que no deben olvidarse porque formaron parte de un trocito de la vida de nuestros antepasado.

\section{Agradecimientos}

Nuestro más sincero agradecimiento a los compañeros del Laboratorio de Evolución Humana de la Universidad de Burgos y al equipo de excavaciones del Portalón y de los yacimientos de la Sierra de Atapuerca. Así mismo agradecemos la colaboración prestada por Marta Negro directora del Museo de Burgos por las facilidades prestadas para la consulta de los materiales del Portalón y de la Galería del Sílex. Esta investigación ha sido financiada por el Ministerio de Educación y Ciencia proyecto n ${ }^{\circ}$ CGL2009-08938-C03-03 y las excavaciones por la Junta de Castilla y León.

\section{BIBLIOGRAFÍA}

1. X. Peñalver, La edad del Hierro. Los Vascones y sus vecinos. El último milenio anterior a nuestra era. Txertoa argitaletxea (Euskal Gaiak Abarka S.L.) Donostia, San Sebastian, (2008)

2. J. Carballo, “De Espeleología. Recientes descubrimientos prehistóricos y geológicos. Pruebas experimentales de la duración de las pinturas. Glíptica en las cavernas. ¿Astronomía prehistórica?". Boletín de la Real Sociedad Española de Historia Natural, 10, págs. 468-481, (1910).

3. H. Breuil, H. Obermaier, "Travaux executés en 1912", L'Anthropologie, 24, págs 5-7, (1913).

4. G. Clark, L.G. Strauss, S.S. Burton, V. Jackson-Clark, "The North Burgos Archaeological Survey. An inventory of cultural remains". En Clark (1979): The North Burgos Archaeological Survey: Bronze and Iron Age archaeology on the Meseta del Norte (Province of Burgos, North-Central Spain). Anthropological Research Papers, 19. Arizona State University. Dept. of Antropology, Arizona, (1979).

5. J. M. Apellániz, S. Domingo, “Estudios sobre Atapuerca (Burgos). II Los materiales de superficie del Santuario de la Galería del Sílex". Cuadernos de Arqueología de Deusto, Bilbao, (1987).

6. J. M. Carretero, A. I. Ortega, L. Juez, A. Pérez-González, J. L. Arsuaga, R. Pérez-MArtínez; M. C. Ortega, A late Pleistocene-Early Holocene archaeological sequence of Portalón de Cueva Mayor (Sierra de Atapuerca, Burgos, Spain), Munibe, 59, págs 67-80, (2008).

7. A. Pérez-Romero, Protohistoria e Historia en el Portalón de Cueva Mayor, Sierra de Atapuerca. Burgos. Máster Tesis, Inédito, (2009).

8. A. Llanos, J. L. Vegas, Ensayo de un método para el estudio y clasificación tipológico de la cerámica, en Estudios de Arqueología Alavesa, VI, Vitoria, págs. 265-313, (1974).

9. A. Castiella Rodríguez, La Edad del Hierro en Navarra y la Rioja. Excavaciones Arqueológicas en Navarra, VIII, Pamplona, (1977).

10. F. Romero Carnicero, Notas sobre la cerámica de la primera Edad del Hierro en la cuenca media del Duero. En Boletín del Seminario de arte y Arqueología, XLVI, Valladolid, págs. 137-153, (1980).

11. J. Llanos, J.M. Apellániz, J. Fariñas, El castro del castillo de Henayo (Alegria, Alava). Campañas de 1969-1970. Estudios de Arqueología Alavesa VIII, págs. 87-212, (1975).

12. J. F. Blanco García, Cerámica Histórica en la Provincia de Segovia. I. Del Neolítico a época Visigoda (V Milenio-711 d.C.) NRT Ediciones. TAH 1, págs. 57-160, (2003).

13. J. J. Fernández Moreno, Cerámica del Redál en el Museo Numantino de Soria". En II Coloquio sobre Historia de la Rioja, Tomo I. Logroño, págs. 55-72, (1986).

14. J. L. Argente, A. Díaz, A. Bescós, Tiermes V. Carratiermes. Necrópolis celtibérica. Memorias, Arqueología en Castilla y León, 9, Valladolid, (2001).

15. J. López De Heredia, Estudio arqueométrico de la cerámica de la Edad del Hierro: Los Castros de Lastra y La Hoya (Álava). Instituto Alavés de Arqueología, págs. 27, (2012).

16. M.A Castiella Rodríguez, La Edad del Hierro en Navarra y Rioja, Pamplona: La Edad del Hierro en Navarra y Rioja, Excavaciones Arqueológicas en Navarra, VIII, (1977).

17. I. Ruíz Vélez, El ritual funerario en las necrópolis burgalesas de la Edad del Hierro. Institución Fernán González. Academia Burgense de Historia y Bellas Artes. Burgos, (2001).

18. J. A. Abásolo Ấlvarez, I. Ruíz Vélez, A. RODRIGUEZ, El Conjunto Arqueológico del Alto de Rodilla (Monasterio de Rodilla, Burgos). En BSAA. LXIX-LXX. Área de Historia del Arte. Áreas de Prehistoria y Arqueología. Universidad de Valladolid, págs. 115-145, (2003-2004).

19. M. A. Arnáiz Alonso, J. Montero Gutiérrez, Facetas del Bronce Final "Regional" en el Alto Ebro y la zona oriental de la Submeseta Norte: manifestaciones arqueológicas y objetos sociales de la Solana (Modular de la Emparedada, Burgos). En Zephyrus, 57, págs. 221-248, (2004). 
20. M. V. Romero Carnicero, Numantia I. La Terra sigillata. E.A.E, 146. Madrid, (1985)

21. M. Beltrán Llopis, Guía de la Cerámica Romana. Libros Pórtico. Zaragoza, (1990)

22. P. de Palol, Clúnia. Guía de las Excavaciones y de la ciudad romana Diputación Provincial de Burgos. Servicio de Investigaciones Arqueológicas, (1969).

23. M. A. Mezquiriz de Catalán, Terra sigillata Hispánica. Vol. 1 y 2, (1961).

24. F. Mayet, Les céramiques à parois fines dans la Péninsule Ibérique. Publications du Center Pierre Paris 1, Paris, (1975).

25. L. Caballero, P. Mateos, y A. Retuerce, Cerámicas tardorromanas y altomedievales en la Península Ibérica. Ruptura y continuidad. II Simposio de arqueología. Mérida 2001. CSIC, Madrid, págs. 321-370, (2003).

26. A. Martínez Salcedo, La cerámica común de época romana en el País Vasco. Vajilla de cocina, mesa y despensa procedente de los asentamientos de Aloria (Álava), Forua (Bizkaia) e Iruña/Veleia (Álava). Tesis Doctoral. Servicio Central de Publicaciones del Gobierno Vasco. Vitoria-Gasteiz, (2004)

27. J.A. Quiros, A. Alonso, Las ocupaciones rupestres en el fin de la Antigüedad. Los materiales cerámicos de Los Husos (Elvillar, Alava) Veleia 24-25, págs. 1123-1142, (2007-2008)

28. M. Vegas, Cerámica Común Romana del Mediterráneo Occidental, (Publicaciones eventuales, 22). Universidad de Barcelona, (1973).

29. F. Mayet, Les céramiques sigillées hispaniques. Contribution à l'histoire économique de la Péninsule Ibérique sous l’Empire Romain, Paris, (1984).

30. J.L. Solaun Bustinza, La cerámica medieval en el País Vasco (Siglos VIIIXIII). Servicio Central de Publicaciones del Gobierno Vasco. Vitoria, (2005)

31. J. Andrió Gonzalo, "Cerámicas altomedievales de Castrogeriz-Burgos". II Coloquio Internacional de Cerámica Medieval en el Mediterráneo Occidental. coord. por Juan Zozaya Stabel-Hansen, Toledo, págs. 233-238, (1986).

32. F. Reyes Téllez, Cerámica medieval de la ermita de la Santa Cruz (Valdezate, Burgos)". EnSegundo Coloquio Internacional de Cerámica Medieval en el Mediterráneo Occidental, coord. por Juan Zozaya StabelHansen, págs. 217-226, (1986).

33. Memorias e Informes de Intervenciones depositados en la Junta de Castilla y León

34. A. I. Ortega, Informe técnico del seguimiento arqueológico previo a la restauración en el Monasterio de San Pedro de Cardeña (Castrillo del Val, Burgos). Junta de Castilla y León. Consejería de Cultura y Bienestar Social. Dirección General del Patrimonio y Promoción Cultural, (1991).

35. J. Andrío, E. Loyola, J. Martínez, J. Moreda, El conjunto arqueológico del monasterio de San Juan de la Hoz de Cillaperlata (Burgos), (1993).

36. M. A. García, J. M. Iglesias, P. Caloca, Excavaciones en Monte Cildá, Olleros de Pisuerga (Palencia), Campañas de 1966 a 1969.Excelentísima Diputación Provincial de Palencia, (1973).

37. R. Bohigas, J. Andrió, J. Peñil, M. García, Las cerámicas medievales no esmaltadas en las provincias de Cantabria, Palencia y Burgos. En La Cerámica Medieval en el Noroeste de la Península Ibérica. Aproximación a su estudio. GUTIÉRREZ GONZÁLEZ, J.A., BOHIGAS ROLDÁN, R. (coord.). Universidad de León, págs. 113-155, (1989).

38. R. Bohigas, P. Sarabia, Camargo. En II Congreso de Arqueología Medieval Española". Madrid, págs. 311-325, (1987).
39. H. Larrén, J. F. Blanco, 0. Villanueva, J. Caballero, A. Domínguez, J. Nuño, F. J. Sanz, G. J. Marcos, M. A Martín, J. Misiego, Ensayo de sistematización de la cerámica tardoantigua en la Cuenca del Duero. En Cerámicas tardorromanas y altomedievales en la Península Ibérica: ruptura y continuidad. II Simposio de arqueología. Mérida, págs. 1-38, (2001).

40. I. García Camino, La Cerámica medieval no esmaltada en la vertiente marítima del País Vasco: los territorios de Bizkaia y Gipuzkoa. En La Cerámica Medieval en el Noroeste de la Península Ibérica. Aproximación a su estudio. GUTIÉRREZ GONZÁLEZ, J. A., BOHIGAS ROLDÁN, R. (coord.). Universidad de León, págs. 87-111, (1989).

41. M. J. Torrecilla Gorbea, Santuario de Nuestra Señora de la Encina (Artziniega) Arkeoikuska: Investigación arqueológica, nº 1999, págs. 157160, (1999).

42. A. Azkarate, Basílica de San Prudencio, en Armentia (Vitoria-Gasteiz) Arkeoikuska: Investigación arqueológica, №. 2005, págs. 180-186, (2005).

43 F. Saénz De Urturi, La cerámica medieval no esmaltada en yacimientos alaveses. En La Cerámica Medieval en el Noroeste de la Península Ibérica. Aproximación a su estudio. GUTIÉRREZ GONZÁLEZ, J. A. y BOHIGAS ROLDÁN, R. (coord.).Universidad de León, págs. 53-86, (1989).

44. A. Turina Gómez, Cerámica medieval y moderna en Zamora. En Arqueología en Castilla y León. Junta de Castilla y León. Diputación de Zamora, (1994).

45. L. M. Llubiá, Cerámica medieval española. Colección Labor. Editorial Labor, (1955).

46. N. Seseña, Talavera y Puente del Arzobispo. Cerámica esmaltada española, Barcelona, págs. 73-92, (1981).

47. J. A., Gutiérrez, Hábitats rupestres altomedievales en la Meseta Norte y Cordillera Cantábrica, Estudios Humanísticos, 4, págs. 29-56, (1982).

48. R. Bohígas, A. Ruíz, Las cerámicas visigodas de poblado en Cantabria y Palencia, Boletín de Arqueología Medieval 3, págs. 31-51, (1989)

49. A. Martínez, M. Unzueta, Estudio del material romano de la cueva de Peña Forua (Forua, Vizcaya), Bilbao, (1988)

50. A. González Blanco (ed.), Los columbarios de la Rioja, Antigüedad y Cristianismo 16, págs. 1-418, (1999).

51. J. M. Gurt, J. M. Palet, Structuration du territoire dans le nord-est de l'Hispanie pendant l'Antiquité Tardive: Transformation du paysage et dynamique du peuplement, en: P. Ouzolias, C. Pellecuer, C.Raynaud, P. Van Ossel y P. Garmy (Dir.): Les campagnes de la Gaule à la fin de l'Antiquité, Antibes, págs. 303-329, (2001).

52. Á. Barrios, I., Martín, Reflexiones sobre el poblamiento rural altomedieval en el Norte de la Península Ibérica, Studia Histórica. Historia Medieval 18-19, págs. 53-83, (2000-2001).

53. E. Riaño, Eremitorios rupestres y colonización altomedieval, Studia Histórica. Historia Medieval 13, págs. 47-58, (1995).

54. J. R., López, Terra Sigillata Hispánica Tardía decorada a molde de la Península Ibérica, Salamanca, (1985).

55. A. Cava, M. A. Beguiristaín, El yacimiento prehistórico del Abrigo de la Peña (Marañón, Navarra), Trabajos de Arqueología Navarra, No 10 , págs. 69-166,(1991-1992)

Recibido: 18/02/2013

Recibida versión corregida: 22/07/2013

Aceptado: 30/07/2013 